University of South Florida

DIGITAL COMMONS

Digital Commons @ University of

@ UNIVERSITY OF SOUTH FLORIDA

South Florida

4-16-2018

\title{
Tracking an Oil Tanker Collision and Spilled Oils in the East China Sea Using Multisensor Day and Night Satellite Imagery
}

\author{
Shaojie Sun \\ University of South Florida \\ Yingcheng Lu \\ University of South Florida \\ Mengqiu Wang \\ University of South Florida \\ Chuanmin $\mathrm{Hu}$ \\ University of South Florida, huc@usf.edu
}

Follow this and additional works at: https://digitalcommons.usf.edu/cimage_pubs

Part of the Marine Biology Commons

\section{Scholar Commons Citation}

Sun, Shaojie; Lu, Yingcheng; Wang, Mengqiu; and Hu, Chuanmin, "Tracking an Oil Tanker Collision and Spilled Oils in the East China Sea Using Multisensor Day and Night Satellite Imagery" (2018). C-IMAGE Publications. 73.

https://digitalcommons.usf.edu/cimage_pubs/73

This Article is brought to you for free and open access by the C-IMAGE Collection at Digital Commons @ University of South Florida. It has been accepted for inclusion in C-IMAGE Publications by an authorized administrator of Digital Commons @ University of South Florida. For more information, please contact digitalcommons@usf.edu. 


\section{Geophysical Research Letters}

\section{RESEARCH LETTER}

10.1002/2018GL077433

Key Points:

- VIIRS nighttime data and windadjusted model show unprecedented value in tracking an oil tanker over $>350 \mathrm{~km}$ after a major collision - Other satellite imagery capture smokes and spilled oils in the East China Sea

- A combination of all remote sensing and modeling efforts proves to be effective in monitoring the tragic accident

\section{Correspondence to:}

C. Hu,

huc@usf.edu

Citation:

Sun, S., Lu, Y., Liu, Y., Wang, M., \& Hu, C. (2018). Tracking an oil tanker collision and spilled oils in the East China Sea using multisensor day and night satellite imagery. Geophysical Research Letters, 45, 3212-3220. https://doi.org/ 10.1002/2018GL077433

Received 1 FEB 2018 Accepted 15 MAR 2018

Accepted article online 23 MAR 2018 Published online 6 APR 2018

\section{Tracking an Oil Tanker Collision and Spilled Oils in the East China Sea Using Multisensor Day and Night Satellite Imagery}

\author{
Shaojie Sun ${ }^{1} \mathbb{D}$, Yingcheng Lu ${ }^{1,2}\left(\mathbb{D}\right.$, Yongxue Liu ${ }^{3}$, Mengqiu Wang ${ }^{1}\left(\mathbb{D}\right.$, and Chuanmin $\mathrm{Hu}^{1}$ \\ ${ }^{1}$ College of Marine Science, University of South Florida, St. Petersburg, FL, USA, ${ }^{2}$ International Institute for Earth System \\ Science, Nanjing University, Nanjing, China, ${ }^{3}$ Department of Geographic Information Science, Nanjing University, Nanjing, \\ China
}

Abstract Satellite remote sensing is well known to play a critical role in monitoring marine accidents such as oil spills, yet the recent SANCHI oil tanker collision event in January 2018 in the East China Sea indicates that traditional techniques using synthetic aperture radar or daytime optical imagery could not provide timely and adequate coverage. In this study, we show the unprecedented value of Visible Infrared Imaging Radiometer Suite (VIIRS) Nightfire product and Day/Night Band data in tracking the oil tanker's drifting pathway and locations when all other means are not as effective for the same purpose. Such pathway and locations can also be reproduced with a numerical model, with root-mean-square error of $<15 \mathrm{~km}$. While high-resolution optical imagery after 4 days of the tanker's sinking reveals much larger oil spill area $\left(>350 \mathrm{~km}^{2}\right)$ than previous reports, the impact of the spilled condensate oil on the marine environment requires further research.

Plain Language Summary The Iranian oil tanker SANCHI collided with a grain freighter on 6 January 2018 in the East China Sea, causing major fires and oil spills. For event response, nighttime data collected by the Visible Infrared Imaging Radiometer Suite (VIIRS) satellite instrument show unprecedented value in monitoring the fires and tracking the $>350 \mathrm{~km}$ drifting pathway of the SANCHI tanker. A numerical model to combine surface currents and wind can also simulate the tanker's locations until it sank on 14 January. Satellite remote sensing during daytime shows smokes and spilled oil on the ocean surface, some of which appears to be oil emulsion. A combination of all available remote sensing and modeling techniques can provide effective means to monitor marine accidents and oil spills to assist event response.

\section{Introduction}

The Iranian oil tanker SANCHI (IMO: 9356608), carrying 1 million U.S. barrels (136,000 metric tons) of condensate oil heading to South Korea from Iran with 32 crews on board, collided with the Chinese grain freighter CF Crystal (IMO: 9497050) in the East China Sea (ECS) at 8 p.m. on 6 January 2018 [Beijing time = GMT + 8 hr; hereafter time used in this paper is all Beijing time; Ministry of Transport of the People's Republic of China (MOT), 2018a]. The accident caused SANCHI on fire and tilted, drifting ablaze for a week, until it exploded and sunk at $\sim 3$ p.m. on 14 January 2018. Three bodies of the 32 crew members were found, with the other 29 missing members presumed dead. During the drift, SANCHI leaked oil since 7 January, according to online reports (MOT, 2018a; State Oceanic Administration (SOA), People's Republic of China 2018a, 2018b). Oil slicks have been observed and reported around the tanker's sinking location since 14 January 2018 through airborne and shipborne surveys (SOA, 2018b).

Monitoring the tanker's drifting pathway and potential spills from a moving target represents a critical need for event response and mitigation. Unfortunately, for this specific event it has proven extremely difficult for two reasons: (1) persistent cloud cover during and after the collision prevented any effective use of optical remote sensing from satellites; (2) the use of synthetic aperture radar (SAR, immune to cloud cover) required a response time, which can vary between hours and days because it includes time for event reporting, image acquisition planning, and execution of image acquisition over the targeted area (IPIECA-IOGP, 2014). Airborne surveys, on the other hand, were limited in space and time. As a result, traditional means through satellite remote sensing and airborne surveys appeared inadequate for event response of this disaster.

Here we demonstrate the unprecedented value of nighttime data collected by the Visible Infrared Imaging Radiometer Suite (VIIRS) in monitoring such an event. Additionally, a numerical model is calibrated using 
Table 1

Number of Days With Imagery or Data Product Coverage From Individual or Multiple Sensors Along the Tanker's Drifting Trajectory (7-14 January 2018) and Around the Tanker Sinking Site (15-18 January 2018)

\begin{tabular}{llcc}
\hline & Satellite sensor/products & 7-14 January & 15-18 January \\
\hline Optical cloud-free coverage & MODIS & 1 & 3 \\
& OLCl & 1 & 1 \\
& VIIRS & 1 & 1 \\
& GOCI & 2 & 3 \\
& ETM+ & 0 & 0 \\
& OLI & 0 & 0 \\
MSI & 1 & 1 \\
SAR coverage & Sentinel-1 & 0 & 1 \\
& Radarsat-2 & 2 & 4 \\
& COSMO-SkyMed & 0 & 0 \\
Fire/Night-light anomalies & TerraSAR-X & 0 & 0 \\
& FIRMS & 2 & 1 \\
& VIIRS Nightfire & 7 & 4 \\
\hline
\end{tabular}

Note. As multiple images/products per day are possible from some sensor(s) (e.g., MODIS Terra and MODIS Aqua, and $\mathrm{GOCl}$ ), the statistics is based on daily frequency (in Beijing time).

these data to track the tanker location, and high-resolution optical satellite imagery collected after 4 days of the tanker sinking shows the area of oil slicks much larger than those reported, which also shows signs of oil emulsions. The objective of this paper is to show the worth of combining all remote sensing imagery (day and night) and numerical modeling in event response, therefore possibly serving as a template when responding to other similar events.

\section{Data and Methods}

\subsection{Satellite Data}

Data from all civilian satellites, whenever available for public access, were downloaded from the corresponding agencies. These include Terra/Aqua Moderate Resolution Imaging Spectroradiometer (MODIS), SuomiNPP VIIRS, Sentinel-3 Ocean and Land Color Instrument (OLCI), COMS Geostationary Ocean Color Imager (GOCl), Landsat ETM+/OLI, Sentinel-2 MultiSpectral Instrument (MSI), and Sentinel-1 SAR. Commercial Radarsat-2, COSMO-SkyMed and TerraSAR-X SAR data archives have also been checked. Detailed information of imagery coverage is provided in Table 1.

After the collision accident, all optical imagery collected during the daytime showed persistent cloud cover until 13 January when the images showed scattered clouds to allow for inspection of some of the pixels. During this period, oil spill detection was impossible but smoke from the burning tanker could be detected on 13 January (see below). Between 7 and 14 January, the above SAR data showed only 2 days of coverage over the tanker's drifting trajectory, while more frequent coverage after the tanker's sinking (on 14 January) was available from COSMO-SkyMed. The Chinese Gaofen-3 (GF-3) satellite launched in 2016 carries a C-band SAR sensor, which works in 12 imaging modes with spatial resolution ranging from $1 \mathrm{~m}$ to $500 \mathrm{~m}$ and swath ranging from 10 to $650 \mathrm{~km}$ (https://chinaspacereport.com/spacecraft/gaofen/). GF-3 was reported to have collected data over the SANCHI location since 8 January (CRESDA, 2018), yet the data were not open to research communities or the public.

Because of the limitations above, the only possibly useful data during the initial phase of the accident were VIIRS nighttime data. There are two types of nighttime data used in this study. The first is the VIIRS Nightfire (v3.0) data product (https://ngdc.noaa.gov/eog/viirs/download_viirs_fire.html), obtained from the National Oceanic and Atmospheric Administration Earth Observation Group every day. A multispectral algorithm was used to detect subpixel hot sources (Elvidge et al., 2013). Candidate hot pixels were first identified by the nighttime M10 $(1,601 \mathrm{~nm})$ band. Six other spectral bands including the Day/Night Band (DNB), M7 $(862 \mathrm{~nm}), \mathrm{M} 8(1,238.5 \mathrm{~nm}), \mathrm{M} 11(2,250 \mathrm{~nm}), \mathrm{M} 12(3,694.5 \mathrm{~nm})$, and M13 $(4,066 \mathrm{~nm})$ were used to confirm the initial detection. A black-body emission curve fitting was then applied to the confirmed hot source 
using these bands, from which the hot source temperature and area were determined (Elvidge et al., 2015). Similar fire products from both MODIS and VIIRS for both day and night were also explored from the Fire Information for Resource Management System (FIRMS, https://firms.modaps.eosdis.nasa.gov/map/). FIRMS uses reflectance and/or brightness temperature thresholds to first classify cloud pixels on both day and night imagery (Giglio et al., 2016; Schroeder et al., 2014) and then mask these pixels from fire detection (Schroeder et al., 2014). Because of the cloud masking before fire detection, FIRMS products showed no valid coverage before 12 January due to persistent cloud cover (Table 1). In contrast, the VIIRS Nightfire algorithm is applied to all pixels, with cloud cover conditions recorded in the final product (Elvidge et al., 2013).

The second type of nighttime data was collected by the low-light imaging DNB (500-900 nm), designed primarily to detect light sources such as city lights (Miller et al., 2013). In this study, VIIRS DNB SDR (Sensor Data Records) calibrated radiance data were obtained from National Oceanic and Atmospheric Administration/Comprehensive Large Array-data Stewardship System (NOAA/CLASS).

Lastly, after persistent cloud cover for many days, MSI images with some cloud-free spots were available on 13 January ( 1 day before the tanker's sinking) and 18 January (4 days after the tanker's sinking). The Level-1C data were processed using the ACOLITE software (https://odnature.naturalsciences.be/remsem/softwareand-data/acolite) to produce spectral Rayleigh-corrected reflectance ( $R_{\mathrm{rc}}$, dimensionless), with all the spectral bands resampled to $10 \mathrm{~m}$ resolution. Red-Green-Blue (RGB) true color $(R=664 \mathrm{~nm}, \mathrm{G}=560 \mathrm{~nm}, \mathrm{~B}=497 \mathrm{~nm})$ images were generated for smoke detection while false-color $R G B$ images $(R=1614 \mathrm{~nm}, \mathrm{G}=835 \mathrm{~nm}, \mathrm{~B}=$ $664 \mathrm{~nm}$ ) were generated to detect spilled oils. Normalized sun glint reflectance $\left(L_{\mathrm{GN}}, \mathrm{sr}^{-1}\right)$ was estimated using the Cox and Munk model and National Centers for Environmental Prediction (NCEP) wind data (Cox \& Munk, 1954; Lu et al., 2016; Wang \& Bailey, 2001). Oil slicks were manually delineated in the ArcMap software (version 10.3) using methods described in Sun et al. (2015)

\subsection{Numerical Model to Track Tanker Locations}

The tanker's drifting pathway was simulated using Global HYCOM daily surface currents and the NCEP Reanalysis daily wind data (10 $\mathrm{m}$ above sea level). HYCOM surface currents data were obtained from the Global Reanalysis (experiment 91.2). A Runge-Kutta fourth-order method was used to model the tanker trajectories with a time step of $15 \mathrm{~min}$. In modeling oil spill trajectory, a factor of $3 \%$ was often applied to wind velocity (IPIECA-IOGP, 2015; Lehr \& Simecek-Beatty, 2000). The large size of the tanker (overall length of $274 \mathrm{~m}$, beam width of $50 \mathrm{~m}$, and full-load draught of $17 \mathrm{~m}$ ) enables a larger cross section (than surface oil) to the wind direction. Therefore, wind was expected to play a more important role than the usual assumption of $3 \%$. A sensitivity test by varying the factor from $1 \%$ to $7 \%$ was conducted to determine the optimal wind factor that led to the least difference between modeled SANCHI locations and observed locations.

\section{Results}

\subsection{SANCHI Locations From VIIRS Night Time Data and Numerical Modeling}

Before 13 January 2018, optical remote sensing data collected by all sensors during daytime were useless due to persistent and complete cloud cover. In contrast, VIIRS nighttime data, specifically the Nightfire data product and DNB data, showed locations of the tanker as well as the size of the hot spot footprint every night starting 8 January (Figure 1). After the tanker's sinking on 14 January, VIIRS showed three separate fire sources in the following night (last panel of Figure 1), indicating surface drifting of floating oil.

The tanker's drifting trajectory could be reproduced by the numerical model (Figure 2). With a wind factor of $4.1 \%$, the modeled tanker locations agreed well with those observed from the VIIRS nighttime data, with a root-mean-square difference of $14.3 \mathrm{~km}$. When other wind factors between $1 \%$ and $7 \%$ were applied, rootmean-square difference was significantly higher (e.g., $40 \mathrm{~km}$ at 3\%).

\subsection{The Value of Optical Remote Sensing Data During Daytime}

On 13 January, after persistent and complete cloud cover since the collision, some optical remote sensing imagery covering the area of interest showed smoke around the tanker location. The example in Figure 3 from the MSI image clearly reveals the smoke, which appears brownish in the RGB image. Wind is about 


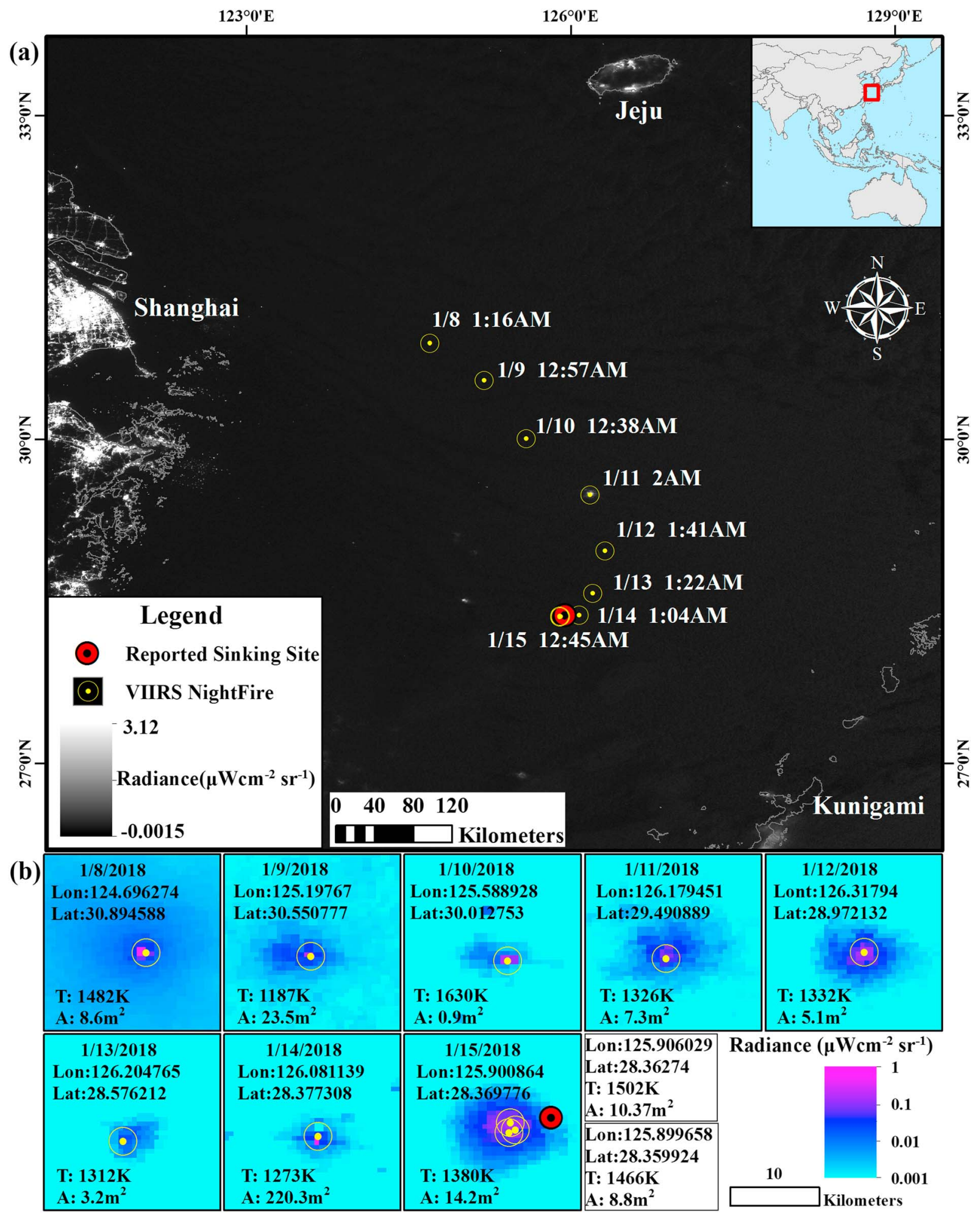

Figure 1. (a) SANCHI oil tanker locations derived from VIIRS Nightfire product in the East China Sea, overlaid on the VIIRS Day/Night Band image captured at 2 a.m. on 11 January 2018. The initial collision was at 8 p.m. on 6 January 2018 (Beijing time $=$ GMT +8 ), while the first VIIRS capture was at 1:16 a.m. on 8 January. The last detection was at 12:45 a.m. on 15 January. SANCHI was reported to sink at 3 p.m. on 14 January (red circle), but fires on ocean surface did not stop until 10 a.m. on 15 January (SOA, 2018b). The sinking location was reported to be $\sim 280 \mathrm{~km}$ southeast of the initial collision location (MOT, 2018b). The VIIRS-based results agree well with both reports. (b) VIIRS Day/Night Band radiance shows local hot spots from 8 to 15 January, with temperature ( $T$, in Kelvins) and location of the hotspot as well as the footprint area $\left(A\right.$, in $\left.\mathrm{m}^{2}\right)$ annotated. Three active fires (yellow dots in the last panel) were detected in the vicinity of the sinking location (red circle in the last panel). 


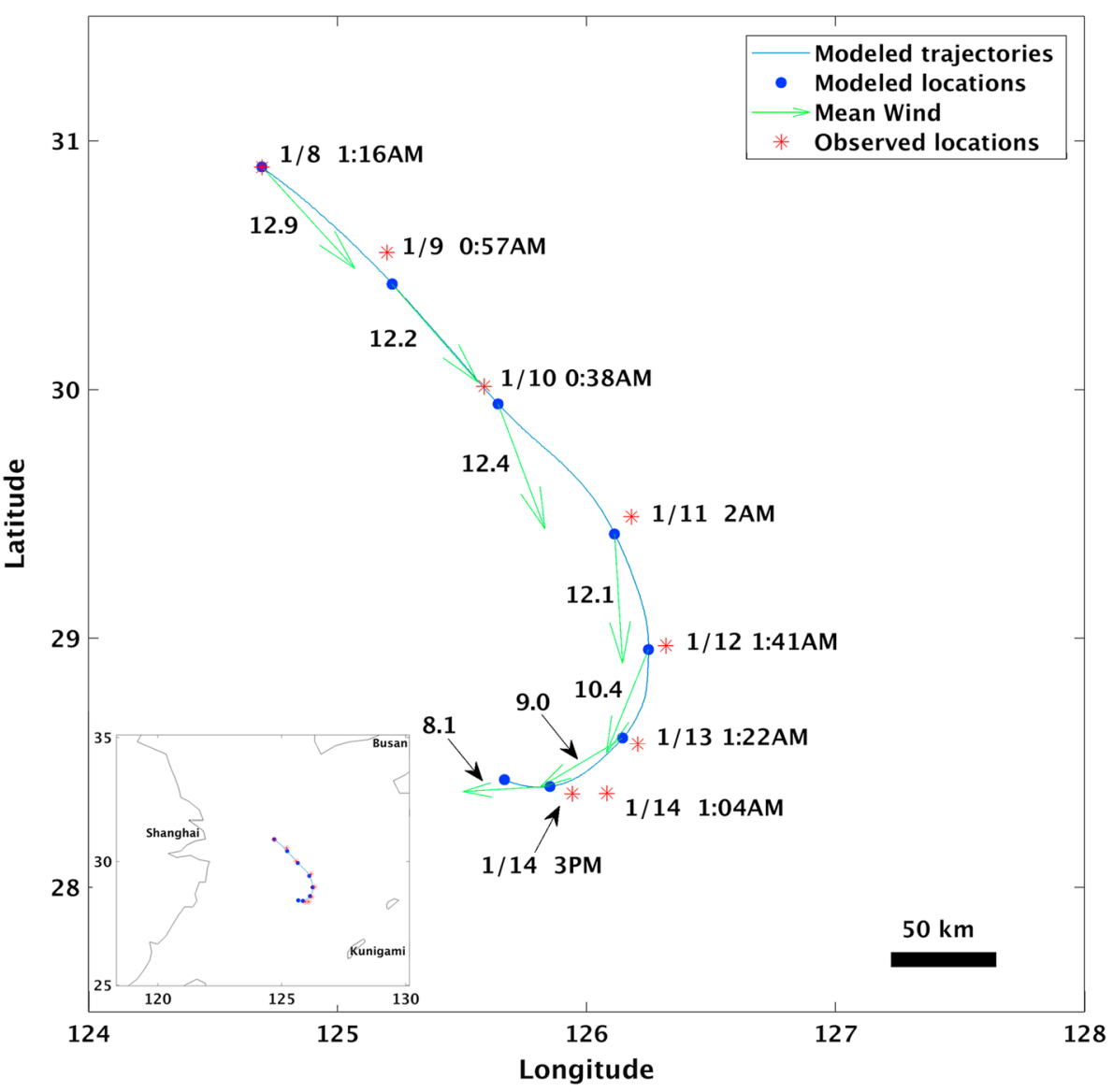

Figure 2. Trajectory and locations of the SANCHI tanker movement determined from VIIRS Nightfire data product (except for the last point at 3 p.m. on 14 January, which is the reported sinking location) and a numerical model. In the model, a $4.1 \%$ factor was applied to wind, which resulted in a minimal root-mean-square difference between modeled and observed locations $(\sim 14.3 \mathrm{~km})$. A $3 \%$ wind factor would lead to RMS difference of $\sim 40 \mathrm{~km}$. Average wind speed and direction for each day are plotted as green arrows, with wind speed $(\mathrm{m} / \mathrm{s})$ annotated to the left of the wind vector.

$8.1 \mathrm{~m} / \mathrm{s}$ blowing from the NNE to SSW. Correspondingly, the smoke is about $15 \mathrm{~km}$ SSW of the tanker's location $9 \mathrm{hr}$ ago, and $14 \mathrm{hr}$ later the tanker's location is to the SSW of the smoke. Other than the smoke, the images could not be used to detect spilled oils due to cloud cover surrounding the smoke area.

Four days after the tanker's sinking, on 18 January, the first high-resolution optical image that could be used to detect spilled oils was captured by MSI (Figure 4). One slick was detected $3 \mathrm{~km}$ north of the sinking location, with a slick size of $\sim 86 \mathrm{~km}^{2}$ elongated in the west to east direction (Figure $4 \mathrm{~b}$, Slick 2). The slick shows mostly negative contrast from water (i.e., darker than water) due to weak sun glint $\left(L_{\mathrm{GN}}=1.5 \mathrm{E}-4 \mathrm{sr}^{-1}\right)$ (Sun \& $\mathrm{Hu}, 2016$ ). Another larger slick was captured 30-40 km northeast of the sinking location, with a slick size of $\sim 270 \mathrm{~km}^{2}$ (Figure 4a, Slick 1). In the center of this slick, some oil stripes in the NNE-SSW direction show signs of oil emulsions as they appear reddish (elevated 1,614 $\mathrm{nm}$ reflectance) in the false-color RGB image (Figure 4a). The NNE-SSW stripes within both slicks in Figures $4 a$ and $4 b$ are apparently due to wind-driven Langmuir circulation, with the direction of the stripes aligned with the NNE-SSW wind direction. These slick size estimations, although biased low due to lack of MSI data coverage to the east of the slicks, are significantly higher than those reported online (SOA, 2018c).

\section{Discussion}

Massive oil spills and possible application of dispersant could cause severe and long-term impacts on the marine ecosystem and local economies (Joye, 2015; Michel et al., 2013; Peterson et al., 2003), thus calling 
$126^{\circ} 0^{\prime} \mathrm{E}$

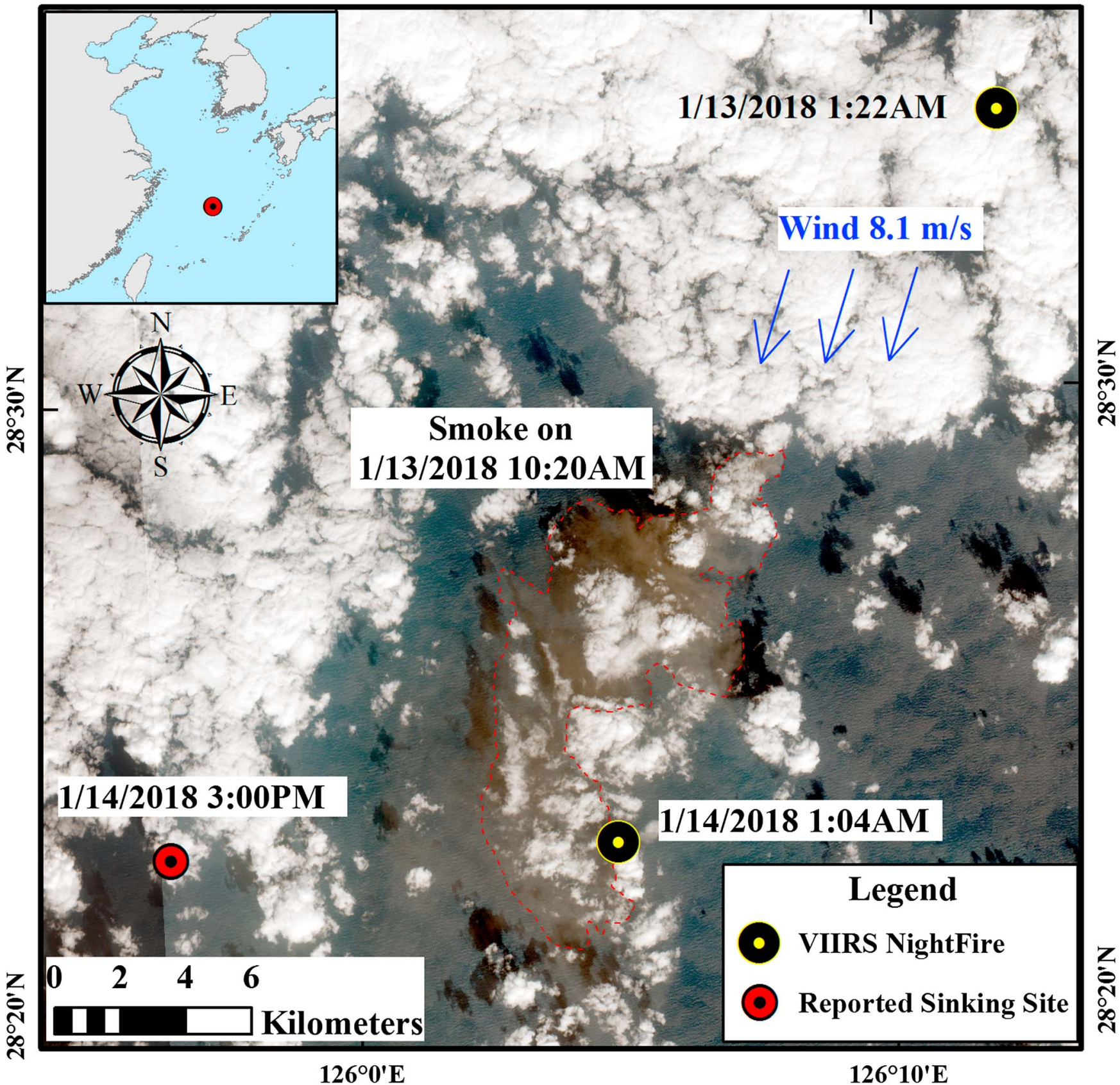

Figure 3. MSI RGB image $(R=664 \mathrm{~nm}, \mathrm{G}=560 \mathrm{~nm}, \mathrm{~B}=497 \mathrm{~nm}$ ) on 13 January 2018 (10:20 a.m.) shows smoke (outlined in red), where VIIRS-detected SANCHI locations on 13 January (1:22 a.m.) and 14 January (1:04 a.m.) are annotated. At the time of imaging, wind blew from northeast to southwest at a speed of $8.1 \mathrm{~m} / \mathrm{s}$.

for accurate and timely assessment during and after the spill. Unfortunately, due to persistent cloud cover and lack of coverage, none of the traditional remote sensing techniques (SAR, daytime optical imagery) proved to be fully effective for this particular event. Here nighttime imagery from VIIRS showed unprecedented value in tracking the tanker's location and fire footprint, thus providing first-hand timely knowledge every night to assist in event response. On the other hand, identifying the tanker's location through locating fires is not trivial, as active fires from gas flares of offshore platforms could confuse the findings. In this study, hot sources from gas flares in the East China Sea were ruled out using a global oil 

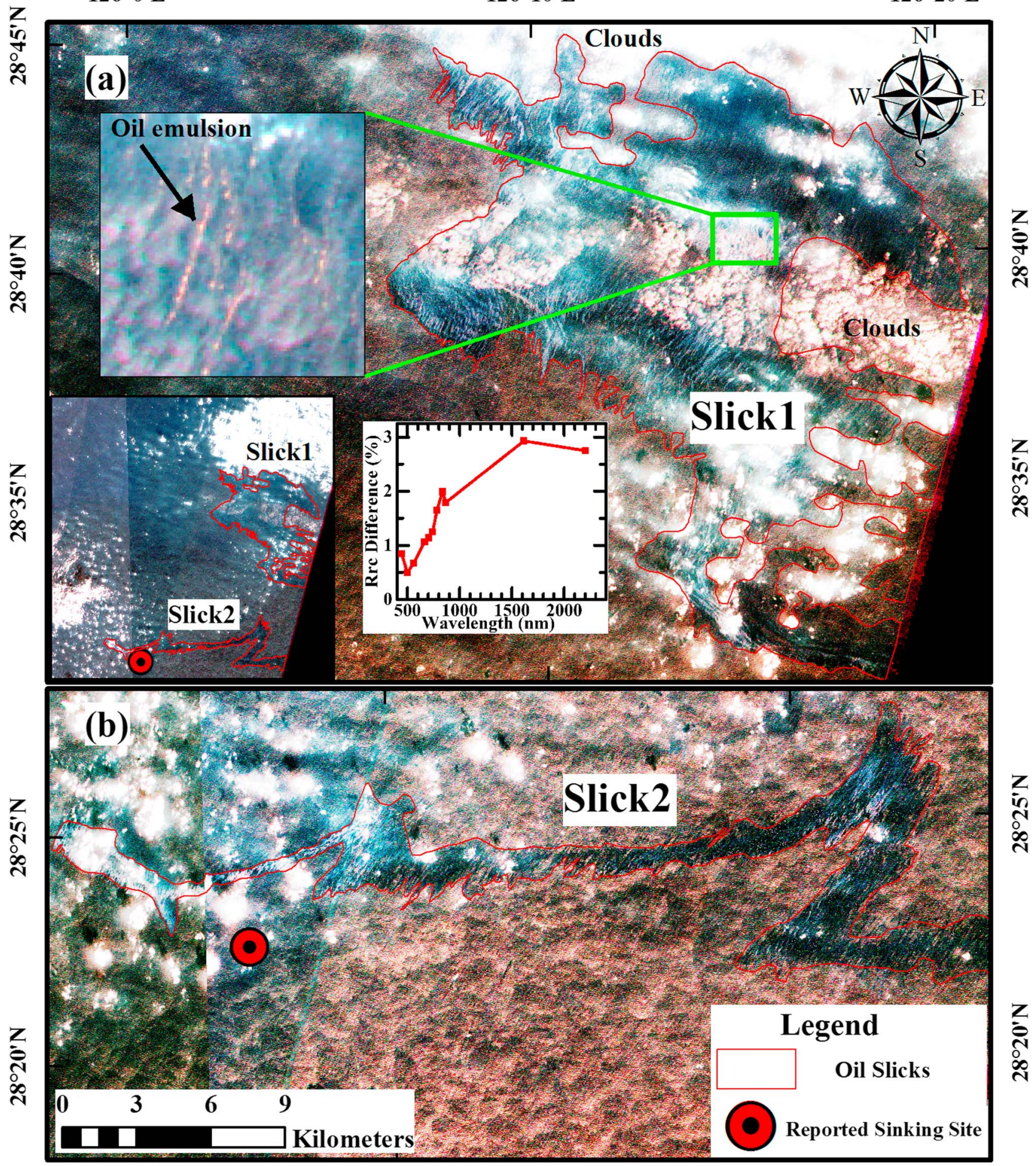

$126^{\circ} 0^{\prime} \mathrm{E}$

$126^{\circ} 10^{\prime} \mathrm{E}$

Figure 4. MSI false-color $R G B$ image $(R=1614 \mathrm{~nm}, \mathrm{G}=835 \mathrm{~nm}, \mathrm{~B}=664 \mathrm{~nm})$ at 10:20 a.m. on 18 January 2018 shows two major slicks (locations annotated in inset figure): (a) Slick 1 is $30-40 \mathrm{~km}$ northeast of the reported sinking site, with a slick size of $\sim 270 \mathrm{~km}^{2}$. This number is an underestimate, as the area east of the oil slick was not covered by the MSI image. The center of the slick shows signs of oil emulsion (enlarged area from the green rectangle) as they appear reddish in the false-color RGB image. Spectral analysis (inset reflectance spectrum) of a randomly selected point (black arrow) shows elevated reflectance at 1,614 nm, a clear indication of oil emulsion. (b) Slick 2 is $3 \mathrm{~km}$ north of the sinking site, with a slick size of $\sim 86 \mathrm{~km}^{2}$ (also underestimated due to lack of MSI coverage to the east). The total area $\left(270+86 \mathrm{~km}^{2}\right)$ is significantly higher than any reported numbers (SOA, 2018c) that ranged between $\sim 160 \mathrm{~km}^{2}$ from field observations and $20.7 \mathrm{~km}{ }^{2}$ from satellite interpretation. The slicks appear darker than water due to the presence of weak sun glint $\left(L_{\mathrm{GN}}=1.5 \mathrm{E}-4 \mathrm{sr}^{-1}\right)$. 
platform database (Liu et al., 2016), making the detection of tanker location reliable. The ability of emissive radiation to penetrate thin clouds makes it possible to detect hot sources even under thin cloud cover, although the temperature of the hot source may contain large degree of uncertainties due to cloud absorption of the radiant emissions (Elvidge et al., 2013).

Oil released to the ocean from this accident was from two sources: the remaining condensate oil after combustion and evaporation, and the remaining bunker fuel or heavy fuel oil. The latter strongly absorbs blue light (Byfield, 1998), while the former is nearly transparent in the visible and near-infrared (NIR) wavelengths $(470-1,000 \mathrm{~nm}$ ) at a thickness of $<200 \mu \mathrm{m}$ (Wettle et al., 2009). Both will dampen the surface wave, thus detectable in SAR imagery (Alpers et al., 2017; Brekke \& Solberg, 2005; Garcia-Pineda et al., 2013), and optical imagery (Adamo et al., 2009; Hu et al., 2009; Pisano et al., 2015; Sun \& Hu, 2016) under optimal wind conditions. Because condensate oil is believed to evaporate fast, it was expected that oil emulsions could not be observed. However, a surprising result from this analysis is that oil emulsion patches appear to have formed on the sea surface after the tanker's sinking (Figure 4). Spectral analysis of selected pixels in the reddish patches of the oil slicks showed significantly elevated reflectance at 1,614 nm (Figure 4a inset), an indication of oil emulsion (Clark et al., 2010; Svejkovsky et al., 2016). Because condensate oil evaporates fast, it is speculated that the oil emulsion originated from the bunker oil released by the tanker after its sinking. Indeed, HYCOM surface currents showed NNE direction after the tanker's sinking, suggesting that the spilled oil could originate from the tanker after its sinking.

By no means does this work de-emphasize the value of SAR and other remote sensing techniques in oil spill response. Instead, the study here is to demonstrate how VIIRS nighttime data can provide critical location information on marine accidents through its unprecedented capacity in identifying fire sources and observing low light at night. Indeed, although due to data restriction policy the commercial SAR data could not be accessed, some quick-look images posted online did show oil slicks in the study region. Additionally, post-sinking MSI imagery showed more spilled oils than those determined from airborne and shipborne surveys, once again proving the value of optical remote sensing. On the other hand, the combination of surface currents and wind data provided a relatively accurate estimate on the tanker's drifting pathway, indicating that numerical modeling can also provide guidance on search and rescue, similar to the search of the Air France 447 in the Equatorial Atlantic (Chen et al., 2012).

Altogether, the multisensor observations from day and night provide way more complete information than any individual sensors alone. This is particularly important for event response during the initial phase as opposed to postevent assessment. For example, without satellite remote sensing providing approximate locations at the very beginning, it would be difficult to narrow down targeted regions to point high-resolution satellite sensors. The case study here demonstrates the value of VIIRS nighttime data in providing such critical information within $30 \mathrm{hr}$ of the accident, therefore complementing other means for event response.

At the time of this writing, postspill assessments are still ongoing, for example, to evaluate the potential impact of the tragic event to the marine environment. Such assessments have proven to be difficult from the Deepwater Horizon oil spill event in the northern Gulf of Mexico in 2010, mainly due to the lack of "baseline" data before the event. Modern satellite remote sensing has provided continuous ocean measurements since 1997 when Sea-viewing Wide Field-of-view Sensor began collecting data, where surface ocean transparency and chlorophyll-a concentration data records may serve as baseline (mean conditions and natural variability) to evaluate the potential impact of the event on nearby ocean environment. Such an impact assessment may be an immediate follow-on study for this tragic event.

\section{Conclusion}

Although VIIRS nighttime data have been widely used to map city lights and fires, this study demonstrates its value in tracking a major collision and oil spill event. More importantly, during the initial days after the collision, VIIRS nighttime data were the only publically available satellite data proven to be effective in tracking the tanker's drifting pathway and daily locations, as all other satellite sensors suffer from lack of coverage or cloud cover. This capacity, along with the numerical tool to track the oil tanker and other sensors to map spilled oil, may serve as a template for similar events in the future. 
Acknowledgments

This work was made possible because of a NASA Earth and Space Science Fellowship (NESSF, grant NNX16AN95H), a grant from the Gulf of Mexico Research Initiative/C-IMAGE II, and support from the National Natural Science Foundation of China (grant 41771376). Data are publicly available through the Gulf of Mexico Research Initiative Information and Data Cooperative (GRIIDC) at https://data. gulfresearchinitiative.org (https://doi. org/10.7266/N7639N85). We thank the European Space Agency for providing Sentinel-1 SAR, MSI and OLCl data (https://scihub.copernicus.eu/), the USGS for providing Landsat data (https://earthexplorer.usgs.gov/), the Korea Ocean Satellite Center for providing $\mathrm{GOCl}$ data (http://kosc.kiost.ac.kr/ eng/p10/kosc_p11.html), NASA for providing FIRMS active fire data and MODIS data (https://oceancolor.gsfc.nasa.gov/), and NOAA for providing VIIRS Nightfire and VIIRS DNB data (https://www.class. ngdc.noaa.gov/saa/products/welcome). We also thank the two anonymous reviewers for their suggestions to improve this manuscript.

\section{References}

Adamo, M., De Carolis, G., De Pasquale, V., \& Pasquariello, G. (2009). Detection and tracking of oil slicks on sun-glittered visible and near infrared satellite imagery. International Journal of Remote Sensing, 30(24), 6403-6427. https://doi.org/10.1080/01431160902865772

Alpers, W., Holt, B., \& Zeng, K. (2017). Oil spill detection by imaging radars: Challenges and pitfalls. Remote Sensing of Environment, 201, 133-147. https://doi.org/10.1016/j.rse.2017.09.002

Brekke, C., \& Solberg, A. H. S. (2005). Oil spill detection by satellite remote sensing. Remote Sensing of Environment, 95(1), 1-13. https://doi. org/10.1016/j.rse.2004.11.015

Byfield, V. (1998). Optical remote sensing of oil in the marine environment (Doctoral dissertation). University of Southampton.

Chen, C., Limeburner, R., Gao, G., Xu, Q., Qi, J., Xue, P., et al. (2012). FVCOM model estimate of the location of Air France 447. Ocean Dynamics, 62(6), 943-952. https://doi.org/10.1007/s10236-012-0537-5

China Center for Resources Satellite Date and Application (2018). Emergency surveillance of tanker collision accident in the East China Sea by earth observing satellites. Retrieved March 9, 2018 from http://www.cresda.com/CN/xwzx/xwdt/11355.shtml

Clark, R. N., Swayze, G. A., Leifer, I., Livo, K. E., Kokaly, R., Hoefen, T., et al. (2010). A method for quantitative mapping of thick oil spills using imaging spectroscopy. US Geological Survey Open-File Report, 1167, 1-51.

Cox, C., \& Munk, W. (1954). Measurement of the roughness of the sea surface from photographs of the Sun's glitter. Journal of the Optical Society of America, 44(11), 838-850. https://doi.org/10.1364/JOSA.44.000838

Elvidge, C., Zhizhin, M., Baugh, K., Hsu, F.-C., \& Ghosh, T. (2015). Methods for global survey of natural gas flaring from visible infrared imaging radiometer suite data. Energies, 9(12), 14. https://doi.org/10.3390/en9010014

Elvidge, C., Zhizhin, M., Hsu, F.-C., \& Baugh, K. (2013). VIIRS Nightfire: Satellite pyrometry at night. Remote Sensing, 5(9), 4423-4449. https://doi. org/10.3390/rs5094423

Garcia-Pineda, O., MacDonald, I., Hu, C., Svejkovsky, J., Hess, M., Dukhovskoy, D., \& Morey, S. (2013). Detection of floating oil anomalies from the Deepwater Horizon oil spill with synthetic aperture radar. Oceanography, 26(2). https://doi.org/10.5670/oceanog.2013.38

Giglio, L., Schroeder, W., \& Justice, C. O. (2016). The collection 6 MODIS active fire detection algorithm and fire products. Remote Sensing of Environment, 178, 31-41. https://doi.org/10.1016/j.rse.2016.02.054

Hu, C., Li, X., Pichel, W. G., \& Muller-Karger, F. E. (2009). Detection of natural oil slicks in the NW Gulf of Mexico using MODIS imagery. Geophysical Research Letters, 36, L01604. https://doi.org/10.1029/2008GL036119

IPIECA-IOGP (2014). An assessment of Surface surveillance capabilities for oil spill response using satellite remote sensing (p. 23). Hampshire, UK, April 2014: IPIECA-IOGP. Retrieved from http://www.ipieca.org/resources/awareness-briefing/an-assessment-of-surface-surveillancecapabilities-for-oil-spill-response-using-satellite-remote-sensing/

IPIECA-IOGP (2015). Aerial observation of oil spills at sea (p. 19). London, February 2015: IPIECA-IOGP. Retrieved from http://www.ipieca.org/ resources/good-practice/aerial-observation-of-oil-spills-at-sea/

Joye, S. B. (2015). Deepwater Horizon, 5 years on. Science, 349(6248), 592-593. https://doi.org/10.1126/science.aab4133

Lehr, W. J., \& Simecek-Beatty, D. (2000). The relation of Langmuir circulation processes to the standard oil spill spreading, dispersion, and transport algorithms. Spill Science \& Technology Bulletin, 6(3-4), 247-253. https://doi.org/10.1016/S1353-2561(01)00043-3

Liu, Y., Sun, C., Yang, Y., Zhou, M., Zhan, W., \& Cheng, W. (2016). Automatic extraction of offshore platforms using time-series Landsat-8 Operational Land Imager data. Remote Sensing of Environment, 175, 73-91. https://doi.org/10.1016/j.rse.2015.12.047

Lu, Y., Sun, S., Zhang, M., Murch, B., \& Hu, C. (2016). Refinement of the critical angle calculation for the contrast reversal of oil slicks under sunglint. Journal of Geophysical Research: Oceans, 121, 148-161. https://doi.org/10.1002/2015JC011001

Michel, J., Owens, E. H., Zengel, S., Graham, A., Nixon, Z., Allard, T., et al. (2013). Extent and degree of shoreline oiling: Deepwater Horizon oil spill, Gulf of Mexico, USA. PLoS One, 8(6), e65087. https://doi.org/10.1371/journal.pone.0065087

Miller, S., Straka, W., Mills, S., Elvidge, C., Lee, T., Solbrig, J., et al. (2013). Illuminating the capabilities of the Suomi National Polar-orbiting Partnership (NPP) Visible Infrared Imaging Radiometer Suite (VIIRS) Day/Night Band. Remote Sensing, 5(12), 6717-6766. https://doi.org/ $10.3390 /$ rs5126717

Ministry of Transport of the People's Republic of China (2018a). Update on oil tanker SANCHI collision and on fire in the East China Sea. Retrieved January 24, 2018 from http://www.mot.gov.cn/jiaotongyaowen/201801/t20180107_2969411.html

Ministry of Transport of the People's Republic of China (2018b). Update on oil tanker SANCHI exploded and sunk yesterday. Retrieved January 24, 2018 from http://www.mot.gov.cn/jiaotongyaowen/201801/t20180115_2972106.html

Peterson, C. H., Rice, S. D., Short, J. W., Esler, D., Bodkin, J. L., Ballachey, B. E., \& Irons, D. B. (2003). Long-term ecosystem response to the Exxon Valdez oil spill. Science, 302(5653), 2082-2086. https://doi.org/10.1126/science.1084282

Pisano, A., Bignami, F., \& Santoleri, R. (2015). Oil spill detection in glint-contaminated near-infrared MODIS imagery. Remote Sensing, 7(1), 1112-1134. https://doi.org/10.3390/rs70101112

Schroeder, W., Oliva, P., Giglio, L., \& Csiszar, I. A. (2014). The new VIIRS 375m active fire detection data product: Algorithm description and initial assessment. Remote Sensing of Environment, 143, 85-96. https://doi.org/10.1016/j.rse.2013.12.008

State Oceanic Administration (SOA), People's Republic of China (2018a). SOA response to SANCHI accident (I). Retrieved January 24,2018 from http://www.soa.gov.cn/xw/hyyw_90/201801/t20180112_59951.html

State Oceanic Administration (SOA), People's Republic of China (2018b). SOA response to SANCHI accident-A joint monitoring effort in East China Sea. Retrieved January 24, 2018 from http://www.soa.gov.cn/xw/hyyw_90/201801/t20180116_59990.html

State Oceanic Administration (SOA), People's Republic of China (2018c). SOA response to SANCHI accident (VII). Retrieved January 24, 2018 from http://www.soa.gov.cn/xw/hyyw_90/201801/t20180118_60031.html

Sun, S., \& Hu, C. (2016). Sun glint requirement for the remote detection of surface oil films. Geophysical Research Letters, 43, 309-316. https:// doi.org/10.1002/2015gl066884

Sun, S., Hu, C., \& Tunnell, J. W. (2015). Surface oil footprint and trajectory of the Ixtoc-I oil spill determined from Landsat/MSS and CZCS observations. Marine Pollution Bulletin, 101(2), 632-641. https://doi.org/10.1016/j.marpolbul.2015.10.036

Svejkovsky, J., Hess, M., Muskat, J., Nedwed, T. J., McCall, J., \& Garcia, O. (2016). Characterization of surface oil thickness distribution patterns observed during the Deepwater Horizon (MC-252) oil spill with aerial and satellite remote sensing. Marine Pollution Bulletin, 110(1), 162-176. https://doi.org/10.1016/j.marpolbul.2016.06.066

Wang, M., \& Bailey, S. W. (2001). Correction of sun glint contamination on the SeaWiFS ocean and atmosphere products. Applied Optics, 40, 4790-4798. https://doi.org/10.1364/AO.40.004790

Wettle, M., Daniel, P. J., Logan, G. A., \& Thankappan, M. (2009). Assessing the effect of hydrocarbon oil type and thickness on a remote sensing signal: A sensitivity study based on the optical properties of two different oil types and the HYMAP and Quickbird sensors. Remote Sensing of Environment, 113(9), 2000-2010. https://doi.org/10.1016/j.rse.2009.05.010 